\title{
PACIENTES SOMATIZADORES NA PSICANÁLISE
}

\author{
Lucas Silva Ferreira ${ }^{1}$
}

Magda Medianeira de Mello²

Resumo: O presente trabalho apresenta a visão teórica de relevantes autores sobre pacientes somatizadores na psicanálise. Trata-se de uma pesquisa qualitativa de cunho exploratório. As bases de dados utilizadas na busca bibliográfica foram as seguintes: Scientific Electronic Library Online (SciELO), Periódicos Eletrônicos de Psicologia (PePSIC), Revista de Psicanálise da Sociedade Psicanalítica de Porto Alegre e livros de psicanálise. Além disto, artigos significativos para a revisão foram buscados nas referências dos estudos que fecharam critérios para a inclusão na revisão. É evidente a aproximação que alguns dos autores fazem da somatização com a psicose, inclusive se utilizam de defesas desta para esclarecer a psicossomática, para outros autores o conceito de clivagem é usado diretamente para explicar o processo de somatização em suas teorias. E como conclusão foi possível notar as diferenças teóricas dos autores ao se posicionarem sobre essa temática, mas todos salientam que a origem dessas patologias remete a conflitos anteriores a fase edípica. Logo a relação primordial entre mãe/bebê, anterior a entrada de um terceiro, é essencial como ponto de origem para explicar as doenças psicossomáticas.

Palavras-chave: Somatização; Doenças psicossomáticas; Psicanálise.

\section{SOMATIC PATIENTS IN PSYCHOANALYSIS}

\begin{abstract}
This paper presents the theoretical view of relevant authors about somatizing patients in psychoanalysis. It's a qualitative research of exploratory nature. The following databases were used in the bibliographic search: Scientific Electronic Library Online (SciELO), Electronic Psychological Journals (PePSIC), Journal of Psychoanalysis of the
\end{abstract}

\footnotetext{
1. Acadêmico do Curso de Bacharelado em Psicologia da UNICNEC.

2 Doutora em Psicologia pela Universidad Autònoma de Madrid. 
Psychoanalytic Society of Porto Alegre (Revista de Psicanálise da Sociedade Psicanalítica de Porto Alegre) and books of psychoanalysis. In addition, the articles selected for review were searched in the references of the studies that achieved the requirements for inclusion in the review. It has been evident the similar approach that some authors do to somatization and psychosis, including using the defense mechanisms to clarify the psychosomatics, but to other authors the concept of cleavage is directly used to explain the process of somatization in their theories. As a conclusion it was possible to notice the theoretical differences of the authors when positioning themselves on the thematic, although all emphasize that the origin of these pathologies refers to the conflicts prior to Oedipus Complex phase. Thus the primordial relationship between mother/baby, previous to the entry of a third-party, is a essential start point to explain psychosomatic diseases.

Keywords: Somatization; Psychosomatic diseases; Psychoanalysis.

\section{INTRODUÇÃO}

A psicanálise com sua descoberta do mecanismo de conversão transformou os pilares do racionalismo cartesiano, introduzindo o conceito de corpo erógeno, colocando como centro desse saber o Inconsciente (GALDI e CAMPOS, 2017).

Segundo Galdi e Campos (2017) a psicanálise, "no geral, considera doença psicossomática todo fenômeno que não se restringe apenas às explicações biológicas médicas, mas que insiste em aparecer, permanecer e que também não se enquadra nos sintomas de neuroses clássicas". Salientam que é um diagnóstico por exclusão.

Segundo Miller (1987) o psicossomático pode ser de uma estruturação mais arcaica do que as do campo da neurose, tendo proximidade com a psicose. Apresentando como característica dificuldades nos processos simbólicos tendo assim como alvo o corpo.

O fenômeno psicossomático diferencia-se do sintoma conversivo dos neuróticos. A diferença reside no fato de que neste último o sintoma ocorre no corpo pulsional, enquanto que no paciente psicossomático o sintoma ocorre no corpo biológico, assim "o sintoma, no campo das neuroses, obedece a uma estrutura de linguagem subjacente, que opera através dos processos da metáfora e do deslocamento, sendo, portanto, carregado de significados 
inconscientes, o que, segundo ele, não ocorre nos fenômenos psicossomáticos" (MILLER, 1987).

Têm sido observadas semelhanças entre fenômenos psicossomáticos e psicoses, como falhas no universo das representações, e no envolvimento do desejo dos pais para com filhos portadores de tais estruturas (MILLER, 1987).

O conceito de psicose atual da psicanalista neozelandesa Joyce McDougall, explicaria os pacientes somatizadores como que constituídos "com base em um núcleo psicótico, a psicose atual remete a uma problemática pré-neurótica, uma vez que não resulta na produção de alucinações ou delírios, mas leva o corpo a se comportar de forma delirante, o que predispõe o sujeito a doenças orgânicas”. Essas doenças seriam disparadas por conflitos de ordem emocional (PERES e SANTOS, 2010; MCDOUGALL, 2013).

Ao que foi exposto, este trabalho apresenta como problema de pesquisa: Qual a visão teórica de relevantes autores sobre pacientes somatizadores na psicanálise?

O presente estudo tem como objetivo geral cotejar as visões de relevantes autores frente à definição de pacientes somatizadores através da psicanálise. E como objetivos específicos: 1) Delimitar a conceituação de pacientes somatizadores na psicanálise; 2) Identificar aspectos comuns entre conceitos pertinentes aos sintomas de somatização na psicanálise; 3) Identificar os aspectos divergentes entre os sintomas de somatização em psicanálise.

Espera-se que os estudos rastreados possam apontar evidências de que pacientes somatizadores apresentem prejuízos em sua capacidade de desenvolver e representar as fantasias inconscientes oriundas das exigências pulsionais e ambientais.

\section{FUNDAMENTAÇÃO TEÓRICA}

\subsection{Pacientes somatizadores na psicanálise: funcionamento psíquico}

O termo psicossomático apareceu na literatura médica pela primeira vez no ano de 1818, pelo psiquiatra alemão Heinroth, tentando descrever uma forma particular de insônia, foi duramente atacado pelo conservadorismo da ciência de sua época (ZIMERMAN, 2007).

A constituição da obra Freudiana relacionadas com os fenômenos histéricos de conversão em que o inconsciente foi descoberto abre as portas de comunicação entre a psique 
e o somático. Nesse fenômeno as paralisias dos membros não eram explicadas por causa orgânicas, inicialmente os médicos da época, inclusive Freud, utiliza da hipnose como tentativa de cura dos sintomas, mas, no entanto a sintomatologia voltava. Somente através da associação livre é que os sintomas puderam ser abrandados ou cessados, inaugurando-se como a principalmente regra de funcionamento da ciência dos fenômenos inconscientes (FREUD, 1895/1996).

Assinala-se que a linguagem não seria capaz de capturar ou organizar tudo, havendo sempre o lugar do não elaborado, recorrendo para vias psicossomáticas. Nesse espaço não caberia às interpretações, mas outro instrumento clínico chamado de construção (FREUD, 1937/1975).

Zimerman (2007) salienta que Freud definiu inúmeros conceitos que servem de base para os estudos modernos sobre os pacientes psicossomáticos. Dentre esses conceitos destacam-se as Representações, onde no desenvolvimento psíquico da representação coisa para representação palavra possibilita a nomeação da palavra e das emoções caóticas; Complacência Somática onde nos mecanismos defensivos das estruturas acontecem somatizações; Fenômeno das Conversões em que os conflitos sexuais inconscientes utilizam o corpo como uma forma de linguagem; dentre outros conceitos.

Dejours (1991) aponta que a somatização pode ser simbolizadora de aspectos perdidos da história da pessoa. Define que a agressividade que não pode ser representada e deriva da clivagem do inconsciente acaba salientando a pulsão de morte que impedida de ser representada no pré-consciente opera no corpo destruindo-o, através das doenças psicossomáticas. Assim, o sujeito pode preservar a sua normalidade diante dos vínculos sociais, através da violência dirigida para o próprio corpo.

A construção do corpo erógeno nunca seria bem sucedida, podendo ocorrer o desapoio da pulsão em alguma área orgânica, a partir de algum traumatismo ocorrido na vida (DEJOURS, 1991). Para Dejours (1991) a pulsão seria de origem orgânica. Algumas somatizações podem abrir espaço para revelar um conflito reprimido demonstrando uma parte oculta da história pessoal do sujeito.

Existem muitas semelhanças no estilo parental na relação entre mãe e bebê dos pacientes psicóticos com os somatizadores. Em que os pais dos primeiros são alienantes do pensamento, enquanto no segundo são destruidores (DEJOURS, 1991). Dejours (1991) propõe que a psicose seria uma somatização que teria como ponto de impacto o sistema 
nervoso ao invés do corpo, onde o desapoio da pulsão ocorreria nas áreas cerebrais responsáveis pela cognição e linguagem.

Avila (2004) menciona que os modelos metapsicológicos da psicanálise psicossomática buscam a compreensão das dimensões da subjetividade expressa nos campos da mente e do corpo.

A psicanalista Joyce McDougall, nascida na Nova Zelândia, mas arraigada na França, foi considerada uma das principais teóricas da psicossomática psicanalítica (PERES e SANTOS, 2010).

O conceito de desafetação é criado pela autora para explicar o processo de somatização. Explica que é um mecanismo que coloca para fora do psiquismo afetos intensos, onde ocorreria um esvaziamento afetivo do simbólico. Exigindo novas formas de liberação da libido que foi ejetada, retornando como nos comportamentos aditivos ou no corpo através das somatizações (MCDOUGALL, 2013).

A somatização se revela como sinal corporal de desejos libidinais proibidos, servindo como defesa contra pulsões agressivas e sádicas anteriores ao período edípico e contra fantasias primitivas oriundas do medo de perder a identidade interna. A tendência de somatizar está presente em todas as estruturas, toda vez que circunstâncias internas ou externas ultrapassam os nossos modos psicológicos de resistências habituais, o psíquico usa o somático como via de escoamento para as pulsões (MCDOUGALL, 2013).

McDougall (2013) descreve que as fragilidades psicossomáticas tem potencial para atingir qualquer pessoa, tendo como origem conflitos da primeira infância. Essa tendência à somatização teria estímulos de eventos estressores, sendo que as ideias desses afetos não seriam simplesmente recalcadas, mas apagadas do psiquismo ou foracluídos ${ }^{3}$ comparados aos estados psicóticos. Indo pela mesma linha de pensamento de MCdougall (2013), Marty (1993) esclarece que mesmo um neurótico, com fortes defesas neuróticas pode se desorganizar e entrar num processo de somatização.

A somatização estaria como uma forma arcaica do funcionamento mental no qual não utiliza a linguagem, mas utiliza o corpo como mecanismo de lidar com emoções dolorosas,

\footnotetext{
${ }^{3}$ A foraclusão é termo criado por Lacan para definir o mecanismo que estaria na origem da estrutura psicótica relacionado com a falha na função paterna, que estaria relacionado com a dificuldade do engajamento da função simbólica (LACAN, 1958/1998). 
arremetendo a única forma de comunicação que os bebês possuem de se comunicarem com suas mães, através do corpo (MCDOUGALL, 2013).

O termo psicossomatose é criado para se referir aos pacientes que somatizam suas angústias, esses possuem uma dificuldade em reconhecer as próprias emoções (alexitimia) é uma linguagem concreta, falta de imaginação (MCDOUGALL, 2013).

A palavra alexitimia (grego a, falta; lexis, palavra; thymos, humor) foi apresentada por Sifneos para se referir aos pacientes que possuem dificuldades em identificar e distinguir entre sentimentos e sensações corporais, dificuldade em reconhecer os sentimentos das outras pessoas sendo acompanhados de grande limitação no processo imaginativo e um modo de funcionar ligado a estímulos externos (SIFNEOS, 1972).

Esses pacientes possuem semelhanças com a psicose onde encontrasse as mesmas angústias inconscientes de representação do corpo como continente e salienta "... os mesmos temores quanto aos limites e à sua estanqueidade, e a partir de fantasias de fusão corporal, um terror idêntico de perder direito à identidade separada, tanto quanto o de ter pensamentos e emoções pessoais" (MCDOUGALL, 2013).

Essas angústias primitivas, presentes em qualquer indivíduo, são resolvidas na fase fálico-edipiana, mas caso isso não ocorra à angústia psicótica domina o quadro clínico (MCDOUGALL, 2013). McDougall (2013) questiona se todas as estruturas não seriam na verdade constituídas a partir de um núcleo psicótico.

Para Winnicott (1966d/1994) a enfermidade no transtorno psicossomático é derivada de uma persistência de uma cisão na organização do ego do paciente, ou de diversas dissociações. Essa dissociação no indivíduo age como uma defesa organizada contra as dificuldades que surgem no decorrer do amadurecimento, sendo que, com tempo e circunstâncias favoráveis, o paciente tenderá a despir-se dessa dissociação. As forças integradoras presentes no indivíduo tendem a fazê-lo a abandonar a defesa (WINNICOTT, 1966d/1994).

Nas concepções de Winnicott (1966d/1994) duas ideias poderiam ser consideradas nessa cisão egóica derivando falhas em um momento mais precoce do amadurecimento do que a outra.

Numa das primeiras hipóteses, mais precoce, poderíamos considerar um frágil estabelecimento da personalização no início do desenvolvimento, relacionado à mãe não 
suficientemente boa, ou seja, um "fracasso materno, o que deixa o bebê sem os elementos essenciais para o funcionamento dos processos maturacionais" (WINNICOTT, 1966d/1994).

A segunda possibilidade do autor se refere às dificuldades à conquista da integração em uma unidade por parte do ego. $\mathrm{O}$ bebê alcança uma integração que lhe permite ser constituído como um EU SOU, separado do mundo não-eu. Uma dificuldade seria lidar com um mundo repudiado do não-eu, tornando- se assim hostil e ameaçador. A teoria Winnicottiana aponta que essa cisão seria uma defesa a esse mundo que tornado hostil, logo repudiado pelo ego que se dá ao longo de linhas psicossomáticas (WINNICOTT, 1966d/1994).

Marty (1993) também salienta o papel da mãe na constituição do psiquismo do paciente psicossomático onde o sintoma se expressaria no corpo por não haver estrutura psíquica na criança diante de uma excitação produzindo uma desorganização da economia psicossomática. O manejo da mãe é fundamental para que essa energia solta possa ser suportável ao novíssimo psiquismo da criança. Assim o papel para-excitante da mãe é salientado por Marty (1993) na constituição psíquica do recém-nascido.

O narcisismo de base é oriundo do amor materno através de todas as satisfações sensoriais responsáveis pelo equilíbrio homeostático. Falhas no sistema psíquico de defesa contra o desamparo materno recorreriam a uma solução somática (MARTY, 1993). Para Marty (1993) pacientes com pensamento operatório encontram- se privado dessa organização narcisista que protegeria o corpo, esse perfil de paciente se encontra uma limitada capacidade simbólica e de representação, se encontram limitados no tempo reproduzindo e ilustrando a ação.

Outra característica salientada por Marty (1993) é a depressão essencial no qual uma depressão sem objeto, sem autoacusação, sem culpabilidade consciente onde o sentimento de desvalorização e de ferida narcísica é levado para a esfera somática. Nessa condição há um apagamento da vida mental, atividade fantasmática e vida onírica com o rebaixamento do tônus libidinal sem contrapartida econômica positiva. Com a lesão de um órgão ocorreria um abrandamento desde estado depressivo inicial, assim o somático seria a última via para lidar com o desamparo.

Roussilon (2012) utiliza o conceito de neutralização energética aproximando-se de Marty. Para ele uma das formas de ligação não simbólica do retorno do clivado é através da 
somatose ou ligação bio-lógica, sendo, o funcionamento operatório, efeito da neutralização energética instaurada para proteger- se de uma experiência aterradora.

A neutralização energética consiste na tentativa de neutralizar o retorno do clivado através de uma organização da vida psíquica restringindo o máximo possível os investimentos de objeto e qualquer relação que possa reativar o trauma primário e o estado de falta que o acompanha. Assim toda relação que possa gerar um retorno da falta será evitada ou congelada por apresentar o risco de reinvestir o estado traumático (ROUSSILON, 2012).

Quanto ao processo de neutralização Roussilon (2012) comenta:

\begin{abstract}
"No processo de neutralização energética simples, que evidentemente se aparenta a formas de depressão fria, ou seja, sem seu cortejo de afetos depressivos, o que é uma diferença clínica notável, tudo parece acontecer como se a psique, confrontada com o fracasso de suas tentativas para integrar a experiencia traumática, conseguisse pôr de lado esta experiência até o momento em que um objeto em nome do amor ou em virtude de uma forma de contrato narcísico extremo, venha resgatar e reavivar ou reaquecer a parte da qual o sujeito teve de se clivar" (ROUSSILON, 2012).
\end{abstract}

A clivagem para Roussilon (2012) seria a base para definir os sofrimentos narcísico-identitários, inclusive no processo de somatização. Nesse conceito a subjetividade ficaria dividida entre uma parte integrada e outra não integrada, sendo uma clivagem no eu. O autor propõe alterações no conceito de clivagem descrito por Freud onde este conceito passaria de uma defesa para uma organização psíquica como ocorre nas patologias do narcisismo, sendo mais uma clivagem no eu do que do eu, fazendo parte desde os primórdios do psiquismo.

$\mathrm{O}$ eu recorreria a esse tipo de organização psíquica para sobreviver ao trauma do desamparo primário, uma experiência de tensão e desprazer sem capacidade simbólica, sem recurso interno ou externo. Nessa situação ocorre um impasse subjetivo que provoca um estado de desespero existencial que põe em risco a própria existência da subjetividade. $\mathrm{O}$ sujeito sente culpa por não ter podido enfrentar aquilo que confrontou (ROUSSILON, 2012).

Nessa situação para sobreviver, o sujeito retira-se da experiência traumática primária e do estado de desamparo experimentado, abrindo mão de sua subjetividade. Contínua “ Garante a sua sobrevivência psíquica - eis o paradoxo - apartando-se da sua vida psíquica subjetiva. Não sente mais o estado traumático, não sente mais o desamparo, não se sente mais no lugar onde está, descentra-se de si mesmo, afasta-se de sua experiência subjetiva" (ROUSSILON, 2012). 
Uma doença somática diante do retorno do estado traumático clivado desempenha o papel de ligar ao corpo aquilo que a psique não conseguiria lidar. Esse processo pode funcionar mantendo uma doença somática em atividade, destinando assim uma função psíquica para esta, ou pode contribuir para produzi- lá, introduzindo as percepções traumáticas vivenciadas no soma (ROUSSILON, 2012).

Na obra de André Green é destacado a aproximação entre os casos-limite e os doentes somáticos, para ele, o funcionamento mental dos estados-limite representam uma base para a compreensão psicanalítica dos fatos psicossomáticos. O seu pensamento era que, atrás da aparente normalidade dos pacientes somatizadores, ocorreria uma loucura em seu interior (AISENSTEIN \& SMADJA, 2013).

Na obra greeniana, o trabalho do negativo seria o responsável pelos processos de somatização. Sendo usado a serviço da desorganização psíquica, cujos efeitos podem submeter à clivagem ao desinvestimento que afeta o sujeito. O negativo nesse sentido é representado pela função desobjetalizante da pulsão de morte (AISENSTEIN \& SMADJA, 2013).

Aisenstein \& Smadja (2013) esclarecem que a pulsão tem o corpo como origem, mas ela tem sentido quando se encontra com o objeto. Assim para Green o objeto é o que revela a pulsão, sendo a pulsão de morte representada pelo mecanismo do desligamento na concepção psicossomática. Nesse procedimento a relação com o objeto é atacada, e o eu entra num processo de morte onde qualquer investimento é rompido e privado para atingir a morte psíquica.

Green salienta que a falha fundamental desses pacientes está relacionada com a construção da subjetividade, onde a falta de objeto fez com que não houvesse a construção de um sujeito (AISENSTEIN \& SMADJA, 2013).

\section{METODOLOGIA}

Trata-se de uma pesquisa qualitativa de cunho exploratório, este tipo de pesquisa tem como objetivo proporcionar maior familiaridade com o problema, com vistas a torná-lo mais explícito ou a construir hipóteses (GIL, 2007). O presente estudo é uma revisão de literatura que constitui a análise científica na interpretação crítica do autor, contribuindo na discussão 
de determinadas temáticas, levantando indagações e colaborando na aquisição e atualização do conhecimento em curto período de tempo (ROTHER, 2007).

As bases de dados utilizadas na busca bibliográfica foram as seguintes: Scientific Electronic Library Online (SciELO), Periódicos Eletrônicos de Psicologia (PePSIC), Revista de Psicanálise da Sociedade Psicanalítica de Porto Alegre e livros de psicanálise. Além disto, artigos relevantes para a revisão foram buscados nas referências dos estudos que fecharam critérios para a inclusão na revisão. Os descritores da busca foram: (1) Doenças psicossomáticas na psicanálise; (2) somatização na psicanálise e (3) psicanálise.

\section{RESULTADOS E DISCUSSÃO}

Esta pesquisa intitulada Pacientes Somatizadores na Psicanálise procurou responder a seguinte questão: Qual a visão teórica de relevantes autores sobre pacientes somatizadores na psicanálise? Como objetivos específicos procurou-se delimitar a conceituação de pacientes somatizadores na psicanálise; identificar aspectos comuns entre conceitos pertinentes aos sintomas de somatização na psicanálise e identificar os aspectos divergentes entre os autores sobre somatização em psicanálise.

A concepção que a presente pesquisa chega quanto à visão dos autores psicanalíticos observados nessa pesquisa sobre a problemática psicossomática deixa claro se tratar de uma questão pré-edípica, e, portanto trata-se de uma situação que o sujeito é afetado muito antes da representação palavra, ou seja anterior a entrada de um terceiro. A pulsão aparece como termo chave para definir a origem das doenças psicossomáticas na maioria dos autores expostos.

Em Dejours (1991) o desapoio da pulsão, responsável pelo processo de somatização, ocorreria por traumas ocorridos na vida. Em Mcdougall (2013) a somatização viria como defesas contra pulsões agressivas anteriores ao período edípico e de fantasias primitivas do medo de perder a identidade.

Para Marty (1993) a psicossomática viria como defesa contra o desamparo materno. O desamparo em Roussilon (2012) aparece como causador de traumas psíquicos na qual o ego seria obrigado a se utilizar da clivagem para sobreviver, a doença somática diante do estado traumático clivado desempenharia o papel de ligar o corpo com aquilo que a psique não conseguiria lidar. 
Na obra de Green o fator psicossomático é colocado ao lado dos estados-limítrofes, mas também utiliza-se da clivagem para explicar a sua concepção, sendo a clivagem ao desinvestimento por parte do objeto que afeta a construção de subjetividade no sujeito, encontrando no corpo sua única forma de expressão (AISENSTEIN \& SMADJA, 2013).

É evidente a aproximação que alguns dos autores fazem da somatização com a psicose, inclusive se utilizam de defesas desta para explicar a psicossomática. McDougall (2013) explicando que a tendência a somatização teria estímulos de eventos estressores, sendo que as ideias desses afetos não seriam simplesmente recalcadas, mas apagadas do psiquismo ou foracluídos, comparando-se aos estados psicóticos.

Dejours (1991) faz diversas comparações entre psicose e somatização, ambas apontando semelhanças no estilo parental na relação entre mãe e bebê dos pacientes psicóticos com os somatizadores. Inclusive propõe que a psicose seria uma somatização que teria como ponto de impacto o sistema nervoso ao invés do corpo, onde o desapoio da pulsão ocorreria nas áreas cerebrais responsáveis pela cognição e linguagem.

O conceito de clivagem é usado diretamente por Dejours (1991), Roussilon (2012) e na obra de André Green conforme salienta Aisenstein \& Smadja (2013) para explicarem o processo de somatização em suas teorias. Sales e cols (2016) ao discorrerem sobre clivagem, salientam que esse termo surge na obra freudiana para explicar a divisão que o ego sofre diante de um sofrimento extremo em que o aparato psíquico não consegue elaborar, esta defesa surge diante do traumático podendo estar presente em todas as estruturas.

Nesse mesmo aspecto tanto Winnicott (1966) quanto McDougall (2013) usam cisão ou foraclusão, ao invés de clivagem, ou seja, defesas exclusivamente psicóticas para se referirem a origem da psicossomatização, mas com o mesmo propósito dos outros autores que se referem a clivagem, ou seja, defesas que surgem para de o ego suportar o trauma frente as falhas ambientais derivadas desde os primórdios da constituição psíquica.

A possibilidade de somatização se estende na maioria dos autores, quase como sendo uma nova estrutura. Outros apontam que essa possibilidade está aberta para todas as estruturas, ou seja, não se limita somente ao perfil padrão que teria maiores possibilidades de escoar o sofrimento no corpo, mas sim na hipótese de que diante do excesso traumático o não representado simbolicamente teria no soma sua tentativa de elaboração (MARTY, 1993; MCDOUGALL, 2013). 
McDougall (2013) explica que a tendência de somatizar está presente em todas as estruturas, toda vez que circunstâncias internas ou externas ultrapassam os nossos modos psicológicos de resistências habituais o psíquico usa o somático como via de escoamento para as pulsões. E Marty (1993) esclarece que mesmo um neurótico, com fortes defesas neuróticas pode se desorganizar e entrar num processo de somatização.

McDougall (2013) se pergunta se na verdade todas as estruturas não seriam constituídas de fundos psicóticos, pois para ela as angústias primitivas, presentes em qualquer indivíduo, seriam resolvidas na fase fálico-edipiana, mas caso isso não ocorra à angústia psicótica domina o quadro clínico ocasionando os processos psicossomáticos.

Dejours (1991) coloca a somatização ao lado das psicoses, Roussilon (2012) os sofrimentos narcísico identitários se destacaria para esse processo e na obra de André Green conforme salienta Aisenstein \& Smadja (2013) o funcionamento dos estados-limite seria a base para explicar as doenças psicossomáticas. E Winnicott (1966d/1994) deixa esclarecido que a enfermidade no transtorno psicossomático é derivada de uma persistência de uma cisão ou de diversas dissociações no ego que agiriam no indivíduo como uma defesa organizada contra as dificuldades encontradas no desenrolar do amadurecimento, sendo que diante de circunstâncias favoráveis essa defesa seria abandonada.

\section{CONSIDERAÇÕES FINAIS}

A presente pesquisa procurou mostrar sucintamente a visão teórica de relevantes autores sobre pacientes somatizadores na psicanálise. Foi possível notar as diferenças teóricas dos autores para explicar essa temática, mas todos salientam que a origem dessas patologias remetem a conflitos anteriores a fase edípica. Logo a relação primordial entre mãe/bebê, anterior a entrada de um terceiro, é essencial como ponto de origem para explicar as doenças psicossomáticas.

O trabalho exposto não teve como objetivo esgotar essa temática, mas apenas demonstrar de maneira ampla a visão de alguns autores pós-freudianos. Sugerisse que pesquisas mais profundas ao longo deste tema possam ser realizadas para ampliar o conhecimento psicanalítico na complexidade do soma/psique.

\section{REFERÊNCIAS BIBLIOGRÁFICAS}


AISENSTEIN, Marilia; SMADJA, Claude. A função desobjetalizante na obra de André Green: um modelo para a psicossomática. Revista de Psicanálise da Sociedade Psicanalítica de Porto Alegre, v. 20, n. 1, p. 89-101, abril, Porto Alegre, 2013.

AVILA, Lazslo Antonio. Um modelo para representar o "irrepresentado" na mente. Trabalho apresentado em Mesa-redonda, no I Congresso Internacional de Psicopatologia Fundamental e VII Congresso Brasileiro de Psicopatologia Fundamental, na PUC-RJ, em 6 de setembro de 2004. Publicado na Revista Latino Americana de Psicopatologia Fundamental ano VIII, $\quad$ n. $\quad 2, \quad$ jun/2005. Disponível em $<$ http://www.scielo.br/pdf/rlpf/v8n2/1415-4714-rlpf-8-2-0187.pdf > acessado aos 26 de agosto de 2019.

CAMPOS, Érico Bruno Viana; GALDI, Maíra Bittar. Modelos teóricos em psicossomática psicanalítica: uma revisão. Temas psicol. vol.25 no.1 Ribeirão Preto. 2017. Disponível em < http://pepsic.bvsalud.org/scielo.php?script=sci_arttext\&pid=S1413-389X2017000100003 > acessado aos 04/04/2019.

DEJOURS, Christophe. Repressão e Subversão em psicossomática: Pesquisas Psicanalíticas sobre o corpo. Editora Jorge Zahar. Rio de Janeiro, 1991.

FREUD, Sigmund. Estudos sobre a histeria. Edição Standard Brasileira das Obras Completas de Sigmund Freud. Rio de Janeiro: Imago, 1996. (Trabalho original publicado em 1895).

FREUD, Sigmund. Construções em análise. Edição standard brasileira das obras psicológicas completas de Sigmund Freud (J. Salomão, trad., Vol. 23, pp. 32-45). Rio Janeiro: Imago, 1975. (Trabalho original publicado em 1937).

GIL, Antônio Carlos. Como elaborar projetos de pesquisa. Ed. Atlas. São Paulo, 2007. 
LACAN, Jaques. De uma questão preliminar a todo tratamento possível da psicose. Ed. Jorge Zahar In J. Lacan, Escritos (pp. 573-590). Rio de Janeiro, 1998. (Trabalho original publicado em 1958).

MAIA, Maria Vitória Campos Mamede; PINHEIRO, Nadja Nara Barbosa. A clínica psicanalítica dos transtornos psicossomáticos: de Freud a Winnicott. Estilos clin. vol.15 no.1 São $\quad$ Paulo 2010. Disponível em $<$ http://pepsic.bvsalud.org/scielo.php?script=sci_arttext\&pid=S1415-71282010000100011> acessado aos 04/04/2019.

MARTY, Pierry. A psicossomática do adulto. Ed. Artes Médicas. Porto Alegre, 1993.

MCDOUGALL, Joyce. Teatros do corpo: o psicossoma em psicanálise. $3^{\text {a }}$ Edição. Editora WMF Martins fontes. São Paulo, 2013.

MILLER, Jacques-Alain. Algumas reflexões sobre o fenômeno psicossomático. In R. Wartel, Psicossomática e Psicanálise (pp. 87-97). Ed. Jorge Zahar. Rio de Janeiro - RJ,1987.

PERES, Rodrigo Sanches; SANTOS, Manoel Antônio dos. O conceito de psicose atual na psicossomática psicanalítica de Joyce McDougall. Revista brasileira de psicanálise vol.44 ñ.1. São $\quad$ Paulo, $2010 . \quad$ Disponível em $<$ http://pepsic.bvsalud.org/scielo.php?script=sci_arttext\&pid=S0486-641X2010000100012 >, acessado aos 27 de abril de 2019.

ROTHER, Edna Terezinha. Revisão sistemática X revisão narrativa. Ed. Acta paulista de Enfermagem. São Paulo, 2007. Disponível em < http://www.scielo.br/scielo.php?script=sci_arttext\&pid=S0103-21002007000200001 > acessado aos 27 de abril de 2019.

ROUSSILLON, René. O desamparo e as tentativas de solução para o traumatismo primário. Revista de Psicanálise da Sociedade Psicanalítica de Porto Alegre, v. 19, n. 2, p. 271-295. Porto Alegre, 2012. 
SALES, Jôse Lane; OLIVEIRA, Regina Herzog de; FERREIRA, Fernanda Pacheco. Clivagem: a noção de trauma desestruturante em Ferenczi. Arq. bras. psicol. vol.68 no.2 Rio de Janeiro ago. 2016. Disponível em < http://pepsic.bvsalud.org/scielo.php?script=sci_arttext\&pid=S1809-52672016000200006 > acessado aos 12 de outubro de 2019.

SIFNEOS, Peter. Short-term psychoterapy and emotional crisis. Harvard University. Cambridge, 1972.

WINNICOTT, Donald. O distúrbio psicossomático. In D. Winnicott Explorações psicanalíticas. Ed. Artes Médicas. Porto Alegre, 1994. (Trabalho original publicado em 1966; respeitando-se a classificação de Huljmand, temos 1966d).

ZIMERMAN, David E. Fundamentos psicanalíticos [recurso eletrônico]: teoria, técnica e clínica: uma abordagem didática / David E. Zimerman. - Dados eletrônicos. - Porto Alegre: Artmed, 2007. 